\title{
Improving Learning Experience of People with Cognitive Disabilities Using Serious Games: A Review
}

\author{
Anirban Chakraborty, Student Member IEEE \\ Eseohen Ojo \\ Bryce Quonoey \\ Gayatri Mehta, Senior Member IEEE \\ University of North Texas, USA
}

Doi:10.19044/esj.2021.v17n35p1

Submitted: 17 September 2021

Accepted: 26 October 2021

Published: 31 October 2021
Copyright 2021 Author(s)

Under Creative Commons BY-NC-ND

4.0 OPEN ACCESS

Cite As:

Chakraborty A., Ojo E., Quonoey B. \& Mehta G. (2021). Improving Learning Experience of People with Cognitive Disabilities Using Serious Games: A Review. European Scientific Journal, ESJ, 17 (35), 1. https://doi.org/10.19044/esj.2021.v17n35p1

\section{Abstract}

Serious games have grown as one of the alternative means to assist people with cognitive and learning disabilities. They have been found to have a positive influence on these people and to help them improve their social skills. They offer them a stress-free environment that assists them in working on their skills at their own pace. Studies have shown that no one game is fit for all kinds of disabilities. Instead, these games must be tailored according to the specific needs of the disability. This paper discusses some of the prevalent serious games and the frameworks that can be used while designing them. Serious games need to be made broadly accessible for people in developing countries to increase their efficacy. Using serious games has helped the disabled to overcome their anxiety, as well as help them in coping with their disability, and its effectiveness to do so is also proven in some studies.

Keywords: Serious Games, Cognitive Disabilities, Intellectual Disabilities

\section{Introduction}

The use of computing machinery like personal computers, smartphones, and video game consoles has become ubiquitous these days. According to a study published by Entertainment Software Association (Pierre-Louis, 2020), 75\% of Americans have at least one video game player 
in their household. While traditional video games were primarily developed for entertainment, the domain of serious games, which are a class of video games or computer games, serves a more specific purpose: imparting an additional goal, such as improving learning. These additional aims are called characterizing goals (Dörner, Göbel, Effelsberg, \& Wiemeyer, 2016). The term Serious Games was first coined by Clark C. Abt in his book "Serious Games" (Abt, 1970). He is also known for providing the very first definition of the phrase: "reduced to its formal essence, a game is an activity among two or more independent decision-makers seeking to achieve their objectives in some limiting context. A more conventional definition would say that a game is a context with rules among adversaries trying to win objectives. We are concerned with serious games in the sense that these games have an explicit and carefully thought-out educational purpose and are not intended to be played primarily for amusement." Serious Games are also defined as games that entertain players as they educate, train, or change their behavior (Stokes, 2005). More recently the definition has been fused in parlance with computer technology: interactive computer application, with or without significant hardware component, that has a challenging goal, is fun to play and engaging, incorporates some scoring mechanism, and supplies the user with skills, knowledge, or attitudes useful in reality (Bergeron, 2006). Serious games provide a learner-centered approach to education wherein the trainee takes full control over the learning process in an interactive framework (Ricciardi \& Paolis, 2014). The game spectrum classification described in (Qin, Chui, Pang, Choi, \& Heng, 2010) describes that computer games are classified into two main spectrums - skills training and fun-based. Serious games lie in the middle of the spectrum and represent games that are developed for nonentertainment purposes and designed for skills development. These games are a blend of realism together with the entertainment factor of a traditional game. Serious games differ from the traditional simulators in four different aspects (Ricciardi \& Paolis, 2014): (1) Entertainment factor, (2) Development costs, (3) Development time, and (4) Deployment cost. Besides serious games, several other techniques as documented in (Akiki, 2014; Amar \& David, 2017; Cacciattolo, 2015; Jacob \& Olisaemeka, 2016) are also prevalent to improve the learning experiences.

Serious games focus primarily on imparting skills and knowledge (Dörner et al., 2016). The development costs are reduced when compared to traditional gaming simulators because they are developed over the existing entertainment gaming platform. The technologies needed to run serious games are widely available among common people, making it easier to deploy the games for all age groups and skill development purposes.

The development of serious games is a relatively newer spectrum in the domain of games with a purpose (GWAP). Various teams come up with 
their own game flow for the serious games that aim towards achieving a goal. However, all these games lack a unifying framework that brings all the diversified perspectives together. The concept of learning through play is quite known (Dewey, 1916; Jean, 1999; Malone, 1981; Papert, 1988). The growth of computer games has consequently aroused interest among researchers to use the platform to impart some knowledge or skill to the players.

This paper presents a comprehensive survey of serious games for various intellectual and cognitive disabilities, including Autism, ADHD, Down's syndrome, and Dyslexia. We also describe how serious games can be used effectively to provide a great learning experience to people with such disabilities. A key element that was observed while studying literature is the adaptation of the serious game for a particular disability. The existing research suggests that serious games be designed with special characteristics keeping in mind the needs of people with a specific disability. For example, what a person with ASD needs the most help with may not be the same thing as what a person with ADHD needs, so a game designed to help people with ASD might not be as beneficial to a person with ADHD. In short, there is not one serious game for all. This paper also stresses the need-based system for serious games development to improve its efficacy. The games need to be specific and tailored towards what each disability group needs.

In addition, the unavailability of serious games in middle to lowincome countries has also been highlighted. This paper also raises the point of spreading serious games to people all over the world. According to (Sharifzadeh et al., 2020) most of the research on serious games has been done on the American and European continents. We must extend these studies and our findings to other parts of the world, especially in developing countries. Aiding the game developers has also been an aim and, to that cause, some simplified models and frameworks have also been cited to assist in future game developments.

\section{Serious Games for Cognitive Development}

People suffering from some cognitive disabilities face difficulties in proper knowledge gaining and all-around competence development. They suffer from disabilities in different ways like proper attention, memory, inadequate problem-solving skills, etc. (Tomé, Pereira, \& Oliveira, 2014). Some of the most common cognitive disabilities are AttentionDeficit/Hyperactivity Disorder (ADHD), Autism Spectrum Disorder (ASD), Down syndrome, and Fragile $\mathrm{X}$ syndrome. Other kinds of disabilities are reported in (Komolafe, 2018; Svestkova \& Sladkova, 2015). While some examples of learning disabilities include dyslexia, speech impairment, and visual impairment. Although they are all categorized as disabilities, they do not entail the same symptoms. People suffering from these disabilities require 
dedicated attention, as traditional approaches to learning fall short in the purpose of learning. They tend to lose interest quickly and hence perform well if the environment is stress-free. Serious games have proven to be one means to address the problems faced by these people (Tomé et al., 2014; Zhonggen, 2019). The instant feedback that these games provide can be highly motivational and beneficial for their learning. There are some pitfalls, however. Some serious games prove to be challenging because they require certain techniques and capabilities that these people cannot deliver. However, they do not feel the pressure of the real world while spending time on a serious game. Since the environment is completely virtual, they feel safe exploring all their decisions and testing their behaviors in a virtual space. Serious games have also proven to be beneficial for people suffering from attention deficit disorder, as these games can capture their interest (Griffiths, 2002) to improve motor coordination and spatial orientation (González, Cabrera, \& Gutiérrez, 2007; Griffiths, 2002). Some studies also suggest that the ability to use computers for impaired people also boosts their self-confidence and pride (Robertson \& Hix, 2002). Besides all these benefits, these games can be tailored to the individual needs of the players, the multiple meanings associated with the games can be more effective in awakening the creativity of the players (Lanyi \& Brown, 2010). (Lanyi \& Brown, 2010) also describes the game on extra time (GOET) project that shows that serious games are used to educate students with cognitive disabilities to increase their chance of employment. To that effect (Lanyi, Brown, Standen, Lewis, \& Butkute, 2010) describes the ten games that were designed and evaluated under the GOET project that can be helpful for other developers looking to venture into the domain of serious games development. A review of the effect of serious games on the intellectually disabled (Hersh \& Leporini, 2018) and people with autism also revealed that serious games have the potential to improve practical, conceptual, cognitive, and social skills (Tsikinas \& Xinogalos, 2019). In a study conducted on children, particularly within students with learning disabilities (Flogie, Aberšek, Aberšek, Lanyi, \& Pesek, 2020), it was also found that serious games could provide a personalized learning environment and hence modification of the game on a one-to-one basis is very much important to increase its efficacy. In addition, the study described in (GarcíaRedondo, García, Areces, Núñez, \& Rodríguez, 2019) has reported a significant improvement in attention performance measures (visual attention). As a result, the research group proposes the deliberate use of serious games to boost the different bits of intelligence, talents, or unique abilities of students with learning disabilities.

In a study mentioned in (Erhel \& Jamet, 2013; Koh, 2020) it is found that intrinsic motivation is increased when players experience the challenges offered by the serious games and that leads to better learning scores in the 
game. Research has also suggested that using serious games rather than traditional methods to educate people is less expensive (Ricciardi \& Paolis, 2014). So, it seems like there is nothing to lose with serious games when they are created with the right elements and used appropriately by educators. Therefore, a lot of focus has now been put on trying to improve and expand the range of serious games available to us.

\section{Essential Elements of Serious Games}

For serious games to appeal to people with learning and cognitive disabilities, they must have some basic elements incorporated in them. They must be able to engage learners while targeting cognitive and social, related skills to improve outcomes of learners. Research has shown that some specific things increase motivation to learn in serious games, as described below:

Creation of a storyline or narrative: Storylines allow learners to feel as though they are experiencing the contents of the game. It also encourages them to look forward to what is next. This allows them to feel attached to the game and increases motivation to learn. Therefore, storylines are an essential element of serious games because it motivates learners.

Goals Direct learning: When medium - and long-term goals are set for the learners, it encourages them to keep playing the game (and essentially keep learning) just so they can achieve these goals. Setting goals for learners in the games also encourage learners to exercise patience. Now, when goals directed learning is combined with storylines, it is highly likely that learners would be very interested and motivated to learn.

Feedback and Rewards: This is very important in serious games because it motivates learners to do better and makes them open to constructive feedback and criticism. Serious games are interactive, and a necessary part of this interaction is constant feedback (whether it be positive or negative) and rewards for good things. Not only do they motivate learners, but they also help build learners' character.

Increasing Levels of Difficulty: While not being too difficult and frustrating for learners to handle, serious games need to be challenging for learners to learn and improve their skills. The sole purpose of this element is to ensure that learners are learning and reaching their best capability while not feeling demotivated.

Provision of Choice: As an interactive game, serious games need to allow their learners to make their own choices in the game. This boosts selfconfidence and encourages the learners to express themselves.

Multiplayer option: Having a multiplayer option in serious games also helps the players learn as they can share their experiences with their peers. This encourages teamwork and ensures that learners do not feel lonely. The 
multiplayer option allows for character development and motivation of learners, so it is essential.

\section{Conceptual Model of Serious Games}

According to (Avila-Pesantez, Delgadillo, \& Rivera, 2019), serious games are based on different theories of learning, which are organized by a set of principles. Constructivism, which is based on problem-solving and making discoveries, social development, humanism, to train experimental knowledge, cognitivism, based on cognitive development and improving learning skills, and behaviorism, based on teaching social skills and programmed instruction. With these principles in mind, (Avila-Pesantez et al., 2019) proposed a conceptual model for serious games. This model comprises four phases: analysis, pre-production, production, and post-production. The first phase comprises coming up with objectives and a target audience, as well as a central concept for the game to revolve around. In the second phase, elements such as a story to complete the objectives, and content such as script and setting, are created. In the production phase, programming will begin with developing game scenarios and user interfaces. Finally, the post-production phase contains the publication and distribution of the game, as well as maintenance, so that the game can be updated as deemed necessary.

Another framework considers the learning and pedagogy theory along with the gaming requirements (Yusoff, Crowder, Gilbert, \& Wills, 2009). The aim is to make the games effective for learning. The conceptual model has the following features: capability includes the cognitive, psychomotor, and possibly effective skills that the players gain while playing the games, while the instructional content is the theme or the concept that the players should learn. Game attributes encompass the factors that make the game engaging and help in the learning process. The goals that are presumed to be achieved during the gameplay session are included in the intended learning outcomes. The measures that must be adopted by the developer of the game to keep the player engaged to make up the learning activity. Based on the gameplay, the player thinks about the next step to be taken in the game and that is found in the reflection stage. The game genre represents the type of game, while game mechanics represent the rules that the players must follow in the game. The amount of learning that the player had while playing the game is represented in the game achievement.

Apart from the above frameworks, (Tsikinas \& Xinogalos, 2018) aim to study the existing serious games frameworks and extract the design guidelines from there and propose a more effective framework to design serious games meant for people with intellectual disabilities. 


\section{Methodologies for Designing Serious Games}

Marne et al. did an excellent job of proposing some methods that need to be implemented when designing a serious game (Marne, Wisdom, HuynhKim-Bang, \& Labat, 2012). The six facets they proposed were: Pedagogical Objectives, Domain Simulation, Interactions with the Simulation, Problems and Progression, Decorum, and Condition of Use. They described Pedagogical Objectives as important in designing a serious game because it involves understanding the way and methods in which an educator educates; the models and methods they use. It is important to understand the educator's methods and get feedback, as an educator is the one who is going to use the game to educate learners. And so, if the methods of the educator are not understood, then the game may not fulfill its purpose in the learners. Domain Simulation involves responding to the learners effectively. When a serious game is being designed, it is important that the game can respond quickly and effectively to learners. Making serious games interactive can benefit learners significantly. Interactions with the Simulation involve considering how learners can conveniently interact with the game when designing the game. This is important because, as mentioned earlier, serious games are interactive games. Without this feature, the game might not be very helpful for people with cognitive disabilities. Problems and progression mean that the game needs to be designed in such a way that it can decide which problems to give to the learners by measuring their progression. This way, the learning will be effective. Decorum involves considering aesthetics and adding fun elements in the game to keep learners engaged. In designing serious games, things like the colors of the characters, the shapes, etc., need to be considered. Finally, the Condition of Use needs to be considered. Designers of serious games need to understand the demographics of the target audience (e.g., age group) i.e., who will play the games. If they do not aim the design of serious games at specific target audiences, then the serious games might not be that effective.

In the same vein (Jaramillo-Alcázar, Venegas, Criollo-C, \& LujánMora, 2021) proposed a list of accessibility guidelines for designing video games for people with disabilities, especially dyslexia. They are listed below:

1. Use simple language.

2. Include subtitles or captions.

3. Use a reasonable font size and style for the words.

4. Use a simple writing style.

5. Ensure a smooth, simple to difficult progression in the game.

6. Remind players of the aim of the game frequently during the game.

7. Provide the players with explicit visual rewards.

8. Put the grayscale in the foreground and the background into consideration.

9. Allow the players to pause when reading instructions and objectives. 
All the above is necessary to establish an effective Game-Based Learning (GBL) environment (Marfisi-Schottman, George, \& TarpinBernard, 2010).

There are also different methods used by researchers to understand individuals' learning abilities and to understand things that serious games offer to people with learning and cognitive disabilities. First, (Marenus, 2020) the Tree of Intelligence (ToI) based on Gardener's Theory of Multiple Intelligences (MIT) explored the multiple possibilities that both serious games and the multiple intelligence approach may offer for improving cognitive components. The Wechsler Intelligence Scale for Children-IV (WISC-IV) was used to determine the participants' intellectual abilities; it provides detailed information on participants' cognitive profiles. The D2 Attention Test (Bates \& Lemay, 2004) was used to assess the attentional variables based on participants' performance; it is a screening test of selective attention and concentration. The EDAH Scale (Zulueta, Díaz-Orueta, Crespo-Eguilaz, \& Torrano, 2018) evaluates attentional symptomatology through the administration of a 20 -item observational skill.

Also, to explain social difficulties in people with cognitive disorders like autism, many people investigate the theory of mind (ToM) approach (Korkmaz, 2011; Premack \& Woodruff, 1978). This approach based on (Premack \& Woodruff, 1978) states that social difficulties in people with cognitive disabilities, especially ASD, come from an inability to recognize the mental state of oneself and other people. This theory serves as a basis for many designs of serious games, like the interactive therapy system (ITS) and much more. (Starks, 2014) also describes in exhaustive detail the unified model for the development of serious games aimed at cognitive development.

\section{Examples of Serious Games for Cognitive Development}

"My First Day at Work" and "The Big Party," described in (Torrente, Blanco, Moreno-Ger, \& Fernández-Manjón, 2012) are two of the popular serious games that are used to treat individuals with cognitive disabilities. When the former is focused on facilitating the incorporation of a new person with a cognitive disability to a new company, the latter is developed to train a specific set of social and self-autonomy skills and concepts in adults with a cognitive disability. Both games allowed players to play at their own pace and comfort, offered a personalized gameplay environment as well. To increase realism during gameplay, both games have also incorporated real-life photos and videos with cartoon-like designs. A key observation in these games was the inability of the players having Down's syndrome to tackle and remember the primary and secondary goals in the game. Observations and findings like these are immensely helpful in developing a serious game that is suited for a particular disability. 
Computer-based games are effectively used to improve the emotional and social skills of people having autism, like improving the emotion and face identity recognition abilities (Tanaka et al., 2010; Wainer \& Ingersoll, 2011) to improving the language and social skills (Grynszpan, Weiss, Perez-Diaz, \& Gal, 2014), etc. Serious games can also help children with autism to learn vocabulary (Khowaja, Salim, \& Al-Thani, 2018). This is possible because individuals having autism embark on activities that can be performed in a safe environment, like computer games (Rice, 2012). The authors (Whyte, Smyth, \& Scherf, 2015) claim that if the principles of serious games can be used in the computer games targeted towards treating autism, then it can lead to an improved outcome. To bolster their claim, the authors have incorporated the findings from other studies (Beaumont \& Sofronoff, 2008; Hopkins et al., 2011) all of which evidenced the incorporation of serious games elements. Computer games for autism treatment should focus on three key aspects (Whyte et al., 2015): (1) use of storyline and goal-directed behaviors, (2) use of cooperative multi-player games that build upon the efficacy of interpersonal interactions in previous virtual reality interventions, and (3) increased use of gaming elements that facilitate the transfer of knowledge and skills from the intervention to more ecologically valid in-person social situations. In 2019 a study was published (García-Redondo et al., 2019) that analyzed the effects in attention on a sample of 44 students having attention deficit hyperactivity disorder (ADHD) and specific learning disorder (SLD), age ranging from six to sixteen years after they were introduced to an educational video game. It was found that there is a significant improvement in attention performance measures (visual attention) after the test. Methodologies to enhance the social skills of children having autism have also been investigated in a game called Social Craft that takes inspiration from a very popular game called Minecraft (Cadieux \& Keenan, 2020). The researchers have updated Minecraft with Social Craft modifications. The primary goal was to enhance the capabilities of the game to strengthen and inculcate social communication skills. Some of the popular games that are available for addressing the issues associated with autism are described below:

1. KickAs-Autism Game ("Game Makes Teenagers with Autism More Independent," n.d.): Adolescents having autism spectrum disorder (ASD) can take part in this game that will allow them to improve their social skills during difficult social scenarios. The gameplay aids them to build a proper insight into social situations and how to cope up with them. This game is being linked to the E-Mental Platform used by therapists.

2. Zirkus Empathica-Autism Game for children ("Effectively Promote Feelings and Empathy in Autism," n.d.): Zirkus Empathica is primarily targeted for the training of socio-emotional competencies within the 
pre and elementary school children with autism. The game is based on a mobile platform, making it easier for the children to get going with the game from the comfort of their homes. The game uplifts the emotional and empathetic competencies of children with autism. In October 2015-October 2016, the app was used by seventy children with autism and the data received from the gameplay validated the app as a therapeutically applicable tool for autism-specific therapy (Dörner et al., 2016).

3. Improving sensitivity to eye gaze cues in autism using serious game technology (Scherf et al., 2018): The developers of the game designed an intervention game that uses the principles of serious games to train people with autism spectrum disorder (ASD) to realize that the eyes, and shifts in gaze specifically, provide information about the external world. The developers believe that this will increase understanding of gaze cues and attention to faces. In the phase I randomized control trial performed, it was found that the game can motivate and increase the skills of people with autism. Interactive Therapy System (ITS) and Sensory Integration Therapy (SIT) have been used in trying to figure out the designs of serious games. ITS is used to assist arm and hand function in children with motor impairment. This is beneficial to children who are diagnosed with autism, as many children with autism also show some degree of motor impairment. (Wille et al., 2009) looked at the use of virtual reality as pediatric ITS. SIT is another form of therapy that can be beneficial for those with ASD by training the processing of neurological information. (Iwanaga et al., 2014) investigated how effective SIT can be for children with high functioning ASD. In a study involving students diagnosed with ASD and Asperger's disorder, the children underwent either SIT or common group therapy (GT) to compare the two. Studies have shown that serious games are very promising in improving the learning experiences of people with ASD.

4. New Horizon game and the SpaceControl application (Carlier, Paelt, Ongenae, Backere, \& Turck, 2020): This application aims at improving the lives of children having ASD and their parents by reducing stress and anxiety using the serious game New Horizon and a supporting parent application, SpaceControl. This application was developed considering the suggestions of therapists and according to the guidelines for e-health patient empowerment. It was observed that the game had some potential to reduce stress and anxiety among children having ASD. This game can also be used as a tool to develop more e-health applications that are geared toward treating children having ASD. 
An example of a serious game that has been used to help people with Down's syndrome is Galaxy Shop (Salah, Abdennadher, \& Atef, 2017). Galaxy Shop focuses on teaching people with Down's Syndrome the advanced numeracy skills needed for their daily life. It has proven to enhance independence in the different aspects concerning numeracy.

Serious games, as a virtual reality game called EnCity (Bourazeri, Bellamy-Wood, \& Arnab, 2017) is also used to engage and encourage young people with Down's Syndrome to have more involvement in the community. By allowing players to complete mini-games that are related to everyday tasks, players gain the required training and encouragement to take part and lead a life without requiring help and support from families and friends.

The use of serious games to analyze Strengths, Weaknesses, Opportunities, and Threats (SWOT) while employing serious games among people with Alzheimer's disease and other related disorders (ADRD) has been systematically assessed (Robert et al., 2014). The aim was to identify practical means to develop serious games that are purposefully geared towards people suffering from this disease. It was found that, if properly developed, then serious games show great potential for people with ADRD. MinWii (Benveniste, Jouvelot, Pin, \& Péquignot, 2012) is a serious video game for people having Alzheimer's and dementia. It is a music therapy-based game that aims to improve the self-image of the patient and reduce behavioral symptoms. In addition, (Shamsuddin, Lesk, \& Ugail, 2011) also provides all the guidelines that the serious games targeted towards people having dementia must possess to provide an effective approach for early detection. The use of artificial intelligence in designing a serious game for people having Alzheimer's has been proposed (Imbeault, Bouchard, \& Bouzouane, 2011). The game can provide an accessible tool for cognitive training and allow the player to estimate the in-game cognitive performance.

(Jaramillo-Alcázar et al., 2021) describes dyslexia as a cognitive disorder that affects the evolutionary ability of people to read, write, and speak. In designing serious games for people with dyslexia, three typical subcomponents of phonological deficits need to be considered: short-term and working phonological memory, Phonological Awareness, and Lexical Access. For children with dyslexia, it is especially important that when designing serious games, things like the font size/design, color patterns, word spacing, and writing style should always be put into consideration.

Serious games can assess the potential risk of Developmental Dyslexia (DD) in children and treat preschoolers who are at risk (Gaggi et al., 2017). This paper describes several games which train unique abilities in children which could benefit those with dyslexia. These games include "Paths", which train both central and peripheral vision by requiring the player to connect a green circle to a yellow circle by following other open circles, thus requiring 
them to distinguish between different images quickly. Another similar game discussed in the paper is called "Local Visual Search," in which the player is shown an image at the start of the game session, which they must recognize and identify among other images. This game helps to train attention, as well as associate different images, which are effective in both visual and auditory settings.

Serious games that would tailor specifically to the needs of children with ADHD would have to include things that are most likely to draw their attention. So, the games could be designed in bright and beautiful colors and objects just to attract the children to it. The games could also be designed in a way where the players could move around while playing them, so they do not lose focus while playing them.

One research paper (Crepaldi et al., 2020) goes over a serious game called Antonyms, which is a computer game for children with ADHD. The game allows the children to interact with environments in various scenarios and requires them to complete different activities based on their selected scenario. The game, therefore, benefited the children with ADHD by allowing them to stay more focused and engaged in the game to achieve fewer errors.

\section{Discussion}

Intellectual disability, as described in (Disabilities, n.d.), is "a disability characterized by significant limitations in both intellectual functioning and in adaptive behavior, which covers many everyday social and practical skills. This disability originates before the age of 22." Therefore, people with intellectual disabilities are found to have a lack of communication skills, self-care capabilities, social skills, academic skills, etc. (Katz \& Lazcano-Ponce, 2008). Impulsive behavior, deficiency in discernment, and short attention span associated with slow learning are also characteristic features of people suffering from intellectual disabilities. Associated with all these are some comorbidities, such as mood and anxiety disorders and stress (Cooper et al., 2015). It is necessary to address these issues and pave some means and infrastructures that will help people suffering from intellectual disabilities to cope with the prevalent norms and standards of society. This will enable them to take care of their daily activities and promote independence.

The research works done on serious games about people with disabilities are few, but many of them yield similar results: that serious games have a positive future in the education sector and that more research needs to be done to ensure that the appropriate serious games are given to target audiences.

Serious games have been found to have some positive influences on people suffering from these kinds of disabilities. It has been found that serious 
games help in acquiring basic skills of daily life (Lopez-Basterretxea, Mendez-Zorrilla, \& Garcia-Zapirain, 2014). These kinds of games have been helpful, because of the stress-free environment it provides these people to undertake challenging activities at their own leisure and more often. This will, eventually, make the rehabilitation more intensive and successful (Sochocka, Mirocha, \& Starypan, 2020). In the presence of a relatively stress-free environment, the learning process becomes more effective.

However, a lack of proper knowledge of the disabilities and their associated problems while designing the serious game can render an inefficient outcome of the game. The effectiveness of the serious games can be vastly improved when the caregivers and the educators employ a balanced approach when applying the game for serious health concerns (Graafland et al., 2014). It has been found that in elders, serious games are as effective as the conventional tests in improving the cognitive abilities (Kueider, Parisi, Gross, \& Rebok, 2012) and much more effective in improving the neuropsychological abilities of patients with alcoholism over the conventional neuropsychological interventions (Gamito et al., 2014). As mentioned before, the application of serious games sounds promising, the Journal of Medical Internet Research ("Journal of Medical Internet Research," n.d.), and the Dutch Society for Simulation in Healthcare ("Dutch Society for Simulation in Healthcare - DSSH," n.d.) have already launched an international peerreviewing initiative to assess the effectiveness of the serious games that are used in healthcare. The healthcare provider must ensure that the serious game suits the need of the user, and this can be done from the following five key areas (Graafland et al., 2014):

1. Game description: The developer must provide an adequate description of the target people for which the serious game applies. This will help the healthcare provider to make a sound assessment of the applicability of the game.

2. Rationale: This will provide information about how the game is going to address the problem which is developed within the people.

3. Functionality: This provides information about how the game can be played and how the instructions in the game are delivered to the user.

4. Validity: From this area, the degree to which the game claims to be successful for the problem must be discerned.

5. Data protection: It must be ensured that the gaming framework is adherent to the prevalent privacy standards for the user. This includes an assessment of how secure the server is that hosts the game and how securely the data is transmitted to and from the server and the medium used by the server, which is usually an electronic device. 
An element of serious concern is, however, the limited accessibility of serious games. (Gentry et al., 2019) describes that research on the effectiveness of serious games has been primarily performed in high-income countries. Therefore, sufficient data on its effectiveness has not been gathered from the low-or middle-income countries. Educators, researchers, and other related professionals can think of new ways to make these games broadly accessible, especially in developing countries.

\section{Conclusion}

The domain of serious games is relatively new. The scientific community has identified the potential benefits of serious games in imparting knowledge and skills to the players. To that effect, several research groups have also conducted their in-house study to test the feasibility of serious games on people with cognitive and learning disabilities. Some results, as discussed before, strongly suggest that serious games can help in the daily activities of disabled people. Overall, it is becoming more obvious that more research needs to be done concerning serious games. There are not enough serious games that meet the specific requirements of each disability. While designing serious games, the learning requirements of people with disabilities need to be met. The increasing shift from traditional learning to more technological learning has also forced professionals to investigate serious games and their advantages. Using an electronic medium sometimes may pose certain difficulties in the study of the effectiveness of serious games in low-income countries. Once the research is extended into these countries, the collected data will provide a further clear and strengthened interpretation of the benefits of serious games for intellectually disabled individuals.

\section{Acknowledgment}

This material is based upon work supported in part by the National Science Foundation under grant no. NSF-CCF-1617475. The authors would also like to express their sincere thanks to Rani Deepika Balavendran Joseph for her useful suggestions while preparing the paper.

\section{References:}

1. Abt, Clark. C. (1970). Serious Games. doi: $10.1177 / 000276427001400113$

2. Akiki, T. K. (2014). A review on effective teaching and learning in higher education. European Scientific Journal, 10(10).

3. Amar, S., \& David, N. B. (2017). Future learning environments for tomorrow's schools. European Scientific Journal, 13(12). doi: 10.19044/esj.2017.v13n12p\%p 
4. Avila-Pesantez, D., Delgadillo, R., \& Rivera, L. A. (2019). Proposal of a conceptual model for serious games design: A case study in children with learning disabilities. IEEE Access, 7, 161017-161033. doi: 10.1109/access.2019.2951380

5. Bates, M. E., \& Lemay, E. P. (2004). The d2 Test of attention: Construct validity and extensions in scoring techniques. Journal of the International Neuropsychological Society, 10(3), 392-400. doi: 10.1017/s135561770410307x

6. Beaumont, R., \& Sofronoff, K. (2008). A multi-component social skills intervention for children with Asperger syndrome: The junior detective training program. Journal of Child Psychology and Psychiatry, 49(7), 743-753. doi: 10.1111/j.1469-7610.2008.01920.x

7. Benveniste, S., Jouvelot, P., Pin, B., \& Péquignot, R. (2012). The MINWii project: Renarcissization of patients suffering from Alzheimer's disease through video game-based music therapy. Entertainment Computing, 3(4), 111-120. doi: 10.1016/j.entcom.2011.12.004

8. Bergeron, B. (2006). Developing Serious Games (Game Development Series). USA: Charles River Media, Inc.

9. Bourazeri, A., Bellamy-Wood, T., \& Arnab, S. (2017). EnCity: A Serious Game for Empowering Young People with Down's Syndrome. 1-6. doi: 10.1109/segah.2017.7939267

10. Cacciattolo, K. (2015). An analysis of how people learn at the place of work .. European Scientific Journal, 11(22).

11. Cadieux, L., \& Keenan, M. (2020). Can social communication skills for children diagnosed with autism spectrum disorder rehearsed inside the video game environment of minecraft generalize to the real world? JMIR Serious Games, 8(2), e14369. doi: 10.2196/14369

12. Carlier, S., Paelt, S. V. der, Ongenae, F., Backere, F. D., \& Turck, F. D. (2020). Empowering children with ASD and their parents: Design of a serious game for anxiety and stress reduction $\uparrow$. Sensors, 20(4), 966. doi: 10.3390/s20040966

13. Cooper, S.-A., McLean, G., Guthrie, B., McConnachie, A., Mercer, S., Sullivan, F., \& Morrison, J. (2015). Multiple physical and mental health comorbidity in adults with intellectual disabilities: populationbased cross-sectional analysis. BMC Family Practice, 16(1), 110. doi: 10.1186/s12875-015-0329-3

14. Crepaldi, M., Colombo, V., Mottura, S., Baldassini, D., Sacco, M., Cancer, A., \& Antonietti, A. (2020). Antonyms: A computer game to improve inhibitory control of impulsivity in children with attention deficit/hyperactivity disorder (ADHD). Information, 11(4), 230. doi: 10.3390/info11040230 
15. Dewey, J. (1916). Democracy and education by John Dewey. Project Gutenberg. Retrieved from https://www.fulltextarchive.com/pdfs/Democracy-and-Education.pdf.

16. Dörner, R., Göbel, S., Effelsberg, W., \& Wiemeyer, J. (Eds.). (2016). Serious Games: Foundations, Concepts and Practice (1st ed.). Cham: Springer. doi: 10.1007/978-3-319-40612-1

17. Effectively promote feelings and empathy in autism. (n.d.). Retrieved July 25, 2021, from https://www.zirkus-empathico.de/.

18. Erhel, S., \& Jamet, E. (2013). Digital game-based learning: Impact of instructions and feedback on motivation and learning effectiveness. Computers \& Education, 67, 156-167. doi: 10.1016/j.compedu.2013.02.019

19. Flogie, A., Aberšek, B., Aberšek, M. K., Lanyi, C. S., \& Pesek, I. (2020). Development and Evaluation of Intelligent Serious Games for Children With Learning Difficulties: Observational Study. JMIR Serious Games, 8(2), e13190. doi: 10.2196/13190

20. Gaggi, O., Palazzi, C. E., Ciman, M., Galiazzo, G., Franceschini, S., Ruffino, M., ... Facoetti, A. (2017). Serious games for early identification of developmental dyslexia. Computers in Entertainment (CIE), 15(2), 1-24. doi: 10.1145/2629558

21. Game makes teenagers with autism more independent. (n.d.). Retrieved July 20, 2021, from https://www.ranj.com/en/cases/gamemakes-teenagers-with-autism-more-independent/.

22. Gamito, P., Oliveira, J., Lopes, P., Brito, R., Morais, D., Silva, D., ... Deus, A. (2014). Executive functioning in alcoholics following an mHealth cognitive stimulation program: Randomized controlled trial. Journal of Medical Internet Research, 16(4), e102. doi: 10.2196/jmir.2923

23. García-Redondo, P., García, T., Areces, D., Núñez, J. C., \& Rodríguez, C. (2019). Serious games and their effect improving attention in students with learning disabilities. International Journal of Environmental Research and Public Health, 16(14), 2480. doi: 10.3390/ijerph16142480

24. Gentry, S. V., Gauthier, A., Ehrstrom, B. L., Wortley, D., Lilienthal, A., Car, L. T., ... Car, J. (2019). Serious gaming and gamification education in health professions: Systematic review. Journal of Medical Internet Research, 21(3), e12994. doi: 10.2196/12994

25. González, J. L., Cabrera, M. J., \& Gutiérrez, F. L. (2007). Using Videogames in Special Education. In M. D. R, P. F, \& Q. A. A (Eds.), Computer Aided Systems Theory -- EUROCAST 2007 (pp. 360-367). Berlin, Heidelberg: Springer Berlin Heidelberg. doi: 10.1007/978-3540-75867-9_46 
26. Graafland, M., Dankbaar, M., Mert, A., Lagro, J., Wit-Zuurendonk, L. D., Schuit, S., ... Schijven, M. (2014). How to systematically assess serious games applied to health care. JMIR Serious Games, 2(2), e11. doi: 10.2196/games.3825

27. Griffiths, M. D. (2002). The educational benefits of video games. Education and Health, 20(3), 47-51.

28. Grynszpan, O., Weiss, P. L. (Tamar), Perez-Diaz, F., \& Gal, E. (2014). Innovative technology-based interventions for autism spectrum disorders: A meta-analysis. Autism, 18(4), 346-361. doi: $10.1177 / 1362361313476767$

29. Hersh, M., \& Leporini, B. (2018). Editorial: Serious games, education and inclusion for disabled people. British Journal of Educational Technology, 49(4), 587-595. doi: 10.1111/bjet.12650

30. Hopkins, I. M., Gower, M. W., Perez, T. A., Smith, D. S., Amthor, F. R., Wimsatt, F. C., \& Biasini, F. J. (2011). Avatar assistant: Improving social skills in students with an ASD through a computer-based intervention. Journal of Autism and Developmental Disorders, 41(11), 1543-1555. doi: 10.1007/s10803-011-1179-z

31. Imbeault, F., Bouchard, B., \& Bouzouane, A. (2011). Serious games in cognitive training for Alzheimer's patients. 2011 IEEE 1st International Conference on Serious Games and Applications for Health (SeGAH), 1-8. doi: 10.1109/segah.2011.6165447

32. Iwanaga, R., Honda, S., Nakane, H., Tanaka, K., Toeda, H., \& Tanaka, G. (2014). Pilot study: Efficacy of sensory integration therapy for Japanese children with high-functioning autism spectrum Disorder. Occupational Therapy International, 21(1), 4-11. doi: 10.1002/oti.1357

33. Jacob, U. S., \& Olisaemeka, A. N. (2016). Inclusive education in the 21st century: Parameters and opportunities for learners with special needs. European Scientific Journal, 12(10), 188 . doi: 10.19044/esj.2016.v12n10p188

34. Jaramillo-Alcázar, A., Venegas, E., Criollo-C, S., \& Luján-Mora, S. (2021). An approach to accessible serious games for people with dyslexia. Sustainability, 13(5), 2507. doi: 10.3390/su13052507

35. Jean, P. (1999). Play, Dreams And Imitation In Childhood. Routledge. doi: $10.4324 / 9781315009698$

36. Katz, G., \& Lazcano-Ponce, E. (2008). Intellectual disability: definition, etiological factors, classification, diagnosis, treatment and prognosis. Salud Pública de México, 50, s132-41. doi: 10.1590/s003636342008000800005

37. Khowaja, K., Salim, S. S., \& Al-Thani, D. (2018). Components to design serious games for children with autism spectrum disorder 
(ASD) to learn vocabulary. 2018 IEEE 5th International Conference on Engineering Technologies and Applied Sciences (ICETAS), 1-7. doi: 10.1109/icetas.2018.8629208

38. Koh, C. (2020). A qualitative meta-analysis on the use of serious games to support learners with intellectual and developmental disabilities: What we know, what we need to know and what we can do. International Journal of Disability, Development and Education, 1-32. doi: 10.1080/1034912x.2020.1746245

39. Komolafe, A. F. (2018). The nexus between fatigue indices and coping strategies in sports among oyo state special athletes. European Scientific Journal, 14(1), 151. doi: 10.19044/esj.2018.v14n1p151

40. Korkmaz, B. (2011). Theory of mind and neurodevelopmental disorders of childhood. Pediatric Research, 69(8), 101-108. doi: 10.1203/pdr.0b013e318212c177

41. Kueider, A. M., Parisi, J. M., Gross, A. L., \& Rebok, G. W. (2012). Computerized cognitive training with older adults: A systematic review. PLoS ONE, 7(7), e40588. doi: 10.1371/journal.pone.0040588

42. Lanyi, C. S., \& Brown, D. J. (2010). Design of serious games for students with intellectual disability. Proceedings of the 2010 International Conference on Interaction Design \&amp; International Development, 44-54. Swindon, GBR: BCS Learning \&amp; Development Ltd. doi: 10.14236/ewic/ihci2010.6

43. Lanyi, C. S., Brown, D. J., Standen, P., Lewis, J., \& Butkute, V. (2010). User interface evaluation of serious games for students with intellectual disability. Computers Helping People with Special Needs, 227-234. Berlin, Heidelberg: Springer Berlin Heidelberg. doi: 10.1007/978-3-642-14097-6_37

44. Lopez-Basterretxea, A., Mendez-Zorrilla, A., \& Garcia-Zapirain, B. (2014). A telemonitoring tool based on serious games addressing money management skills for people with intellectual disability. International Journal of Environmental Research and Public Health, 11(3), 2361-2380. doi: 10.3390/ijerph110302361

45. Malone, T. W. (1981). Toward a theory of intrinsically motivating instruction. Cognitive Science, 5(4), 333-369. doi: 10.1016/s03640213(81)80017-1

46. Marenus, M. (2020). Gardner's Theory of Multiple Intelligences | Simply Psychology. Retrieved August 14, 2021, from Gardner's Theory of Multiple Intelligences website: https://www.simplypsychology.org/multiple-intelligences.html.

47. Marfisi-Schottman, I., George, S., \& Tarpin-Bernard, F. (2010). Tools and methods for efficiently designing serious games. 226-234. Retrieved from https://www.scopus.com/inward/record.uri?eid=2- 
s2.0-

79960317843\&partnerID=40\&md5=3bd83224ba27f $1896837654 \mathrm{~d} 04$ $25 \mathrm{c} 5 \mathrm{~b} 1$.

48. Marne, B., Wisdom, J., Huynh-Kim-Bang, B., \& Labat, J.-M. (2012). The Six Facets of Serious Game Design: A Methodology Enhanced by Our Design Pattern Library. 21st Century Learning for 21st Century Skills, 208-221. Berlin, Heidelberg: Springer. doi: 10.1007/978-3642-33263-0_17

49. Papert, S. (1988). Does Easy Do It? Children, Games, and Learning. Game Developer Magazine. Retrieved from http://papert.org/articles/Doeseasydoit.html.

50. Pierre-Louis, S. (2020). Essential facts about the computer and video game industry (p. 24). Entertainment Software Association. Retrieved from Entertainment Software Association website: https://www.theesa.com/wp-content/uploads/2020/07/2020-

ESA_Essential_facts_070820_Final_lowres.pdf.

51. Premack, D., \& Woodruff, G. (1978). Does the chimpanzee have a theory of mind? Behavioral and Brain Sciences, 1(4), 515-526. doi: 10.1017/s0140525x00076512

52. Qin, J., Chui, Y.-P., Pang, W.-M., Choi, K.-S., \& Heng, P.-A. (2010). Learning blood management in orthopedic surgery through gameplay. IEEE Computer Graphics and Applications, 30(2), 45-57. doi: 10.1109/mcg.2009.83

53. Ricciardi, F., \& Paolis, L. T. D. (2014). A comprehensive review of serious games in health professions. International Journal of Computer Games Technology, 2014, 1-11. doi: 10.1155/2014/787968

54. Rice, J. W. (2012). The gamification of learning and instruction: Game-based methods and strategies for training and education. International Journal of Gaming and Computer-Mediated Simulations (IJGCMS), 4(4), 81-83. doi: 10.4018/jgcms.2012100106

55. Robert, P. H., König, A., Amieva, H., Andrieu, S., Bremond, F., Bullock, R., ... Manera, V. (2014). Recommendations for the use of Serious Games in people with Alzheimer's Disease, related disorders and frailty. Frontiers in Aging Neuroscience, 6, 54. doi: 10.3389/fnagi.2014.00054

56. Robertson, G. L., \& Hix, D. (2002). Making the computer accessible to mentally retarded adults. Communications of the ACM, 45(4), 171183. doi: $10.1145 / 505248.506006$

57. Salah, J., Abdennadher, S., \& Atef, S. (2017). Galaxy shop: Projectionbased numeracy game for teenagers with Downs Syndrome. Serious Games, 109-120. Cham: Springer International Publishing. doi: 10.1007/978-3-319-70111-0_10 
58. Scherf, K. S., Griffin, J. W., Judy, B., Whyte, E. M., Geier, C. F., Elbich, D., \& Smyth, J. M. (2018). Improving sensitivity to eye gaze cues in autism using serious game technology: study protocol for a phase I randomised controlled trial. BMJ Open, 8(9), e023682. doi: 10.1136/bmjopen-2018-023682

59. Shamsuddin, S. W., Lesk, V., \& Ugail, H. (2011). Virtual environment design guidelines for elderly people in early detection of dementia. Zenodo, 5, 603-607. doi: 10.5281/zenodo. 1054980

60. Sharifzadeh, N., Kharrazi, H., Nazari, E., Tabesh, H., Khodabandeh, M. E., Heidari, S., \& Tara, M. (2020). Health education serious games targeting health care providers, patients, and public health users: Scoping review. JMIR Serious Games, 8(1), e13459. doi: $10.2196 / 13459$

61. Sochocka, A., Mirocha, J., \& Starypan, R. (2020). Serious games as an aid in the development of people with intellectual disabilities. BioAlgorithms and Med-Systems, 16(1), 20190055. doi: 10.1515/bams2019-0055

62. Starks, K. (2014). Cognitive behavioral game design: a unified model for designing serious games. Frontiers in Psychology, 5, 28. doi: 10.3389/fpsyg.2014.00028

63. Stokes, B. (2005). Videogames have changed: time to consider 'Serious Games'? The Development Education Journal. Retrieved from http://hdl.handle.net/1961/auislandora:63571

64. Svestkova, O., \& Sladkova, P. (2015). System of prevocational rehabilitation in the Czech Republic. European Scientific Journal, 11(10).

65. Tanaka, J. W., Wolf, J. M., Klaiman, C., Koenig, K., Cockburn, J., Herlihy, L., ... Schultz, R. T. (2010). Using computerized games to teach face recognition skills to children with autism spectrum disorder: the Let's Face It! program. Journal of Child Psychology and Psychiatry, 51(8), 944-952. doi: 10.1111/j.1469-7610.2010.02258.x

66. Tomé, R. M., Pereira, J. M., \& Oliveira, M. (2014). Using serious games for cognitive disabilities. Serious Games Development and Applications, 34-47. Cham: Springer. doi: 10.1007/978-3-319-116235_4

67. Torrente, J., Blanco, Á. del, Moreno-Ger, P., \& Fernández-Manjón, B. (2012). Designing serious games for adult students with cognitive disabilities. In T. Huang, Zhigang Zeng, Chuandong Li, \& Chi Sing Leung (Eds.), Neural Information Processing (pp. 603-610). Berlin, Heidelberg: Springer. doi: 10.1007/978-3-642-34478-7_73

68. Tsikinas, S., \& Xinogalos, S. (2018). Designing effective serious games for people with intellectual disabilities. 2018 IEEE Global 
Engineering Education Conference (EDUCON), 1896-1903. doi: 10.1109/educon.2018.8363467

69. Tsikinas, S., \& Xinogalos, S. (2019). Studying the effects of computer serious games on people with intellectual disabilities or autism spectrum disorder: A systematic literature review. Journal of Computer Assisted Learning, 35(1), 61-73. doi: 10.1111/jcal.12311

70. Wainer, A. L., \& Ingersoll, B. R. (2011). The use of innovative computer technology for teaching social communication to individuals with autism spectrum disorders. Research in Autism Spectrum Disorders, 5(1), 96-107. doi: 10.1016/j.rasd.2010.08.002

71. Whyte, E. M., Smyth, J. M., \& Scherf, K. S. (2015). Designing serious game interventions for individuals with autism. Journal of Autism and Developmental Disorders, 45(12), 3820-3831. doi: 10.1007/s10803014-2333-1

72. Wille, D., Eng, K., Holper, L., Chevrier, E., Hauser, Y., Kiper, D., ... Meyer-Heim, A. (2009). Virtual reality-based pediatric interactive therapy system (PITS) for improvement of arm and hand function in children with motor impairment - a pilot study. Developmental Neurorehabilitation, 12(1), 44-52. doi: 10.1080/17518420902773117

73. Yusoff, A., Crowder, R., Gilbert, L., \& Wills, G. (2009). A Conceptual Framework for Serious Games. 1-4. doi: 10.1109/icalt.2009.19

74. Zhonggen, Y. (2019). A meta-analysis of use of serious games in education over a decade. International Journal of Computer Games Technology, 2019, 1-8. doi: 10.1155/2019/4797032

75. Zulueta, A., Díaz-Orueta, U., Crespo-Eguilaz, N., \& Torrano, F. (2018). Virtual reality-based assessment and rating scales in ADHD diagnosis. Psicología Educativa, 25(1), 13-22. doi: 10.5093/psed2018a18 